\title{
Effects of monosodium glutamate treatment on calretinin-immunoreactive neurons in hippocampus of postnatal rats
}

\author{
Karol Rycerz, Aleksandra Krawczyk, Jadwiga Jaworska-Adamu, Izabela Krawczyk-Marc
}

Department of Animal Anatomy and Histology, University of Life Sciences, Lublin, Poland

\begin{abstract}
Introduction. Calretinin (CR) is a protein, which is present in GABAergic neurons and belongs to the calciumbinding proteins family. It may reduce the excitotoxicity phenomenon through its $\mathrm{Ca}^{2+}$ buffering properties. This phenomenon is due to the increase of calcium ions levels caused by the excess of glutamate - the main excitatory neurotransmitter. The aim of the study was to investigate alterations of calretinin-immunoreactivity in neurons of hippocampal CA1 region and dentate gyrus with hilus in 10 day-old rats treated with monosodium glutamate (MSG).

Material and methods. Ten 7 day-old Wistar rats were used. The MSG-group consisted of 5 MSG-treated rats at a dose of $4 \mathrm{~g} / \mathrm{kg}$ b.w. for 3 consecutive days and the second group consisted of 5 control animals. After euthanasia the brains containing hippocampus were dissected and embedded in paraffin blocks. The immunohistochemical peroxidase-antiperoxydase reaction was performed on tissue sections. The morphometric analyses of CR-immunopositive neurons: density, percentage ratio to the density of all cells and an assessment of digital immunostaining intensity were performed.

Results. The distribution of the CR-immunoreactive neurons in the hippocampus was irregular. In the MSGgroup there were single cells, which were more intensely stained than in control animals. Some of cells contained processes of different length. The density of CR-immunopositive cells and their percentage ratio to the density of all cells did not change significantly after MSG treatment. However, there was a statistically significant increase in the staining intensity of CR-immunopositive cells.

Conclusions. The obtained results indicate that CR-positive cells in P7-P10 rats are only slightly affected by MSG in CA1 region and dentate gyrus with hilus of the hippocampus. (Folia Histochemica et Cytobiologica 2014, Vol. 52, No. 4, 281-288)
\end{abstract}

Key words: calretinin; neurons; hippocampus; rats; monosodium glutamate

\section{Introduction}

Calretinin (CR) belongs to EF-hand calcium binding proteins family. It contains six motifs of which five have the ability to bind the calcium ions. CR appears earlier than other calcium binding proteins in central nervous system (CNS) [1-3]. It is a sensory protein

Correspondence address: K. Rycerz, DVM. Department of Animal Anatomy and Histology Faculty of Veterinary Medicine, University of Life Sciences Akademicka St. 12, 20-950 Lublin, Poland e-mail: karol.rycerz@up.lublin.pl included in the regulation of intracellular processes in brain. Moreover, it maintains appropriate calcium ions concentration in cells as a slow and fast buffer. The buffer participates in modulation of neurons activity and synaptic plasticity. This protein takes part in cell cycle regulation, proliferation, differentiation and death. CR may be involved in the process of neurogenesis in the hippocampus, because a transient expression of the protein was revealed in cells postmitotic stadium of dentate gyrus. Calcium binding proteins which may reduce the influence of cytotoxins, including $\mathrm{CR}$, are responsible for decreasing the excess of free $\mathrm{Ca}^{2+}$ ions fractions in neurons [4-7].

Glutamate $(\mathrm{Glu})$ is a main excitatory neurotransmitter in the mammalian CNS. Some authors indicate 
that about $90 \%$ of neurons and also astrocytes are sensitive to its effects by stimulation of appropriate receptors [8]. Excess of glutamate may initiate excitotoxicity, which leads to alterations or even death of nervous and glial cells [9]. After neuronal excitation the released glutamate from glutamatergic neurons affects the target cells by activation of inter alia metabotropic receptors (mGluR1 and mGluR5). It leads to ion channels opening and $\mathrm{Ca}^{2+}$ influx to neurons and astrocytes cytoplasm $[10,11]$. Astrocytes uptake most of Glu and in pathological conditions they release the neurotransmitter into intercellular space under the influence of calcium ions. These processes affect neurons which release Glu in excess into the synaptic clefts. Then it acts on N-methyl-D-aspartate ionotropic receptors (NMDA), which cause hyperexcitability of nervous cells. It may lead to metabolic disorders in cells and in consequence to their death $[9,12]$.

Glutamate as a main excitatory neurotransmitter and inhibitory gamma-aminobutyric acid (GABA) are playing a crucial role in functioning of hippocampus and dentate gyrus [13].

In rat, hippocampus proper was divided into CA1-CA4 regions which exhibit laminar structure. The regions contain: alveus (A), stratum oriens (SO), stratum pyramidale (SP), stratum radiatum (SR), stratum lacunosum-moleculare (SLM). Dentate gyrus with hilus contains: stratum moleculare (SM) and stratum granulare (SG) [14]. In these areas of the brain there are two types of neurons: principal and interneurons. Both of them contain Glu and GABA receptors. Principal, pyramidal, glutamatergic cells represent $70-80 \%$ of total neuronal population in hippocampus and granular neurons make up about $90 \%$ of the population in dentate gyrus. Inhibitory interneurons are present in both hippocampus and dentate gyrus. They are the smallest population of nonpyramidal cells, which constitute about $10-25 \%$ of the total number of neurons $[15,16]$. Interneurons present different shapes: stellate, oval and fusiform [17]. Local interneurons connect with each other and with principal excitatory cells creating a net included in neuronal activity control. Functionally one of the groups of interneurons is a subpopulation of GABA-ergic cells containing neuropeptides: cholecystokinin (CCK), somatostatin (SOM), vasoactive intestinal peptide (VIP), calbindin D28k (CB) and calretinin (CR). Another subclass of interneurons consists of basket cells containing $\mathrm{CR}$ and SOM. Interneurons from both subclasses are the regular spiking cells (RS). Interneurons with $\mathrm{CR}$ are able to regulate internal neuronal stimulation and with other calcium binding proteins they synchronise stimulation rhythm and induce long-term potentiation (LTP) [18]. Primary neurons and interneurons are particularly important in the memory and learning processes in hippocampus [16]. This area of the brain participates in information intensification transforming short-term memory into long-term memory and it is also responsible for the spatial memory. Different morphological and functional changes in neurons and their connections influence these processes $[13,19]$.

Monosodium glutamate (MSG) administrated to experimental animals causes selective neurodegenerative damage in some areas of the brain. This phenomenon can be reduced by the increase in calcium binding proteins levels, including calretinin, which provides calcium ions buffering properties in neurons. The blood-brain barrier (BBB) is not fully developed in young individuals, thus they may be exposed to MSG toxic effects [20-23]. In rat's hippocampus and cerebral cortex the largest growth of blood vessels falls on 10 day of postnatal life [24, 25].

Therefore, the aim of the study was to investigate alterations of calcium binding protein - calretinin - immunoreactivity in neurons of hippocampal CA1 region and dentate gyrus with hilus in 10 days old rats (P10) after monosodium glutamate treatment. The morphological and morphometric assessment of nervous cells was conducted in both studied brain areas.

\section{Material and methods}

This study was conducted on ten, 7 days-old (P7) male Wistar rats. Animals were kept in appropriate conditions (controlled temperature $-20-22^{\circ} \mathrm{C}, 12 \mathrm{~h}$ light-dark cycle) with their dams and received mother's milk. The dams were kept one to a cage with free access to food and water. Experiments were performed according to the agreement of Second Local Ethical Committee (7/2011). Male rats were divided into two groups: control and experimental. Experimental animals were injected subcutaneously with 4 $\mathrm{g} / \mathrm{kg}$ b.w. monosodium glutamate (L-Glutamic acid monosodium salt monohydrate, Sigma-Aldrich, St. Louis, Missouri, USA) for 3 consecutive days. Control group was treated with $0.9 \%$ physiological saline administrated by the same route and in the same frame of time. All 10 days old animals (P10) were euthanized $24 \mathrm{~h}$ after the last injection and their brains were dissected. The material was fixed in buffered $10 \%$ formalin for $12 \mathrm{~h}$ and subsequently the paraffin blocks were prepared using a routine histological technique. The blocks with hippocampus localised in the temporal lobe of the cerebral cortex were cut with microtome (A $4230 \mu \mathrm{m}-\mathrm{A}$ $3750 \mu \mathrm{m}$, according to the atlas by König and Klippel) [26]. Frontal $6 \mu \mathrm{m}$-thick sections containing hippocampus were placed on slides, deparaffinised in xylene, and hydrated in a graded series of alcohols. 
Immunohistochemistry. In order to demonstrate the immunoreactivity of calretinin in neurons indirect immunohistochemical peroxidase-antiperoxydase reaction (PAP) was performed. Sections were treated with $0.4 \% \mathrm{H}_{2} \mathrm{O}_{2}$ at room temperature for $30 \mathrm{~min}$ to inhibit the endogenous peroxidase. After rinsing in $0.5 \mathrm{M}$ TRIS buffer (TBS, $\mathrm{pH}$ $=7.6$ ) the sections were incubated in normal goat serum at room temperature for $20 \mathrm{~min}$ in order to eliminate background staining. A set of antibodies and reagents (Sigma-Aldrich, St. Louis, Missouri, USA) diluted with 0.5 M TBS according to producer's recommendations were used to conduct immunohistochemical PAP reaction. The primary antibody was the specific monoclonal rabbit anti-CR antibody (incubation for $48 \mathrm{~h}$ at $4^{\circ} \mathrm{C}$ ), and the second was the monoclonal goat anti-IgG antibody (Sigma-Aldrich). Next the monoclonal peroxidase-antiperoxydase complex was applied. The 5,5'-diaminobenzidine tetrahydrochloride (DAB, Sigma-Aldrich) was used as a chromogen. Then sections were rinsed in distilled $\mathrm{H}_{2} \mathrm{O}$ and counterstained with Mayer's haematoxylin. Next, sections were dehydrated, cleared in xylene and mounted with DPX (Fluka, Buchs, Switzerland). Specificity control in which the primary antibody was omitted or replaced with normal goat serum was carried out.

Morphometric analysis. Calretinin-immunopositive neurons of hippocampus CA1 region, dentate gyrus and hilus were analysed and photographed under the Olympus BX51 light microscope (Olympus, Tokyo, Japan) with digital camera (Olympus Color View III). For the microscopic assessment and photography the sections ( 20 per animal) were chosen randomly from all collected sections from each animal. Photomicrographs ( 2 for CA1 and 2 for dentate gyrus with hilus per section) were archived and next the morphometric analyses were performed with the Cell ${ }^{\wedge} \mathrm{D}$ programme (Olympus). A grid with squares of $2.5 \times 10^{-3} \mathrm{~mm}^{2}$ was imposed on randomly chosen photomicrographs from CA1 region and dentate gyrus with hilus. The size of the squares was selected in a way that the test area was the same for all layers of the studied regions. Only the squares which entirely covered the studied layer [stratum oriens (SO), stratum pyramidale (SP), stratum radiatum (SR), stratum lacunosum-moleculare (SLM) of CA1, stratum moleculare (SM) and stratum granulare (SG) of dentate gyrus with hilus] were chosen to be counted, but not more than 3 squares per photo in one layer. CR-positive and CR-negative cells were counted in 20 squares in each layer per animal (80 squares throughout CA1 and 60 squares throughout dentate gyrus with hilus per animal), which resulted in the measurements of 100 squares in the control rats and MSG-treated rats per each studied layer. To study the immunostaining intensity CR-positive cells were consecutively selected during counting until the result from 10 cells per each animal was provided, which gives
50 cells from each group from every studied area. Each section was individually evaluated and scored in a blinded fashion by one of authors (I. K-M). The density of immunopositive cells and their percentage ratio to the density of all cells were specified. The density of all cells including CR-immunonegative and CR-immunopositive cells was also compared between experimental and control groups. The intensity of CR-positive reaction was described as weak $(+)$, moderate $(++)$ and intense $(+++)$. The digital immunostaining intensity was morphometrically specified in nuclei as optical units per $\mu \mathrm{m}^{2}\left(\mathrm{ou} / \mu \mathrm{m}^{2}\right)$ in each rat of both groups.

Statistical analysis. The results were statistically analysed with the R 3.0.2 programme (Free Software Foundation's GNU General Public License, http://www.r-project.org/). Results were compared with nonparametric Kruskal-Wallis test. ANOVA test with post hoc tests: Tuckey HSD and Scheffe's tests were used to compare the digital immunostaining intensity between both groups of animals.

\section{Results}

\section{Calretinin immunoreactivity in hippocampus of monosodium glutamate-treated neonatal rats}

CR-immunoreactive neurons were unevenly distributed in all hippocampal CA1 region layers in both groups of animals. Single, oval cells with moderate $(++)$ or intense $(+++)$ CR-immunoreactivity were observed in stratum oriens and stratum pyramidale (Figures 1 and 2). These neurons were characterised by the presence of cytoplasmic and nuclear reaction. However, their nuclei were repeatedly more intensely stained than their cytoplasm. CR-immunopositive neurons of MSG-treated rats had single and short processes in stratum pyramidale of the CA1 region. CR-immunostained neurons with intense $(+++)$ cytoplasmic and nuclear reaction were observed very seldom in stratum radiatum and stratum lacunosum -moleculare. In these two layers, similarly as in stratum pyramidale, cells were characterised by the presence of short processes. In control animals there were cells with weak or moderate staining intensity and without nervous processes (Figures 1 and 2). In experimental group some CR-immunonegative neurons demonstrated dark and shrunken nuclei.

In MSG-treated neonatal rats in stratum moleculare and stratum granulosum of dentate gyrus there were single, oval neurons with cytoplasmic and nuclear, intensive or moderate CR-immunoreactivity (Figures 3 and 4). Short, brown processes extended from neuronal bodies. In dentate gyrus of control animals oval CR-immunopositive cells with weak $(+)$ or moderate 


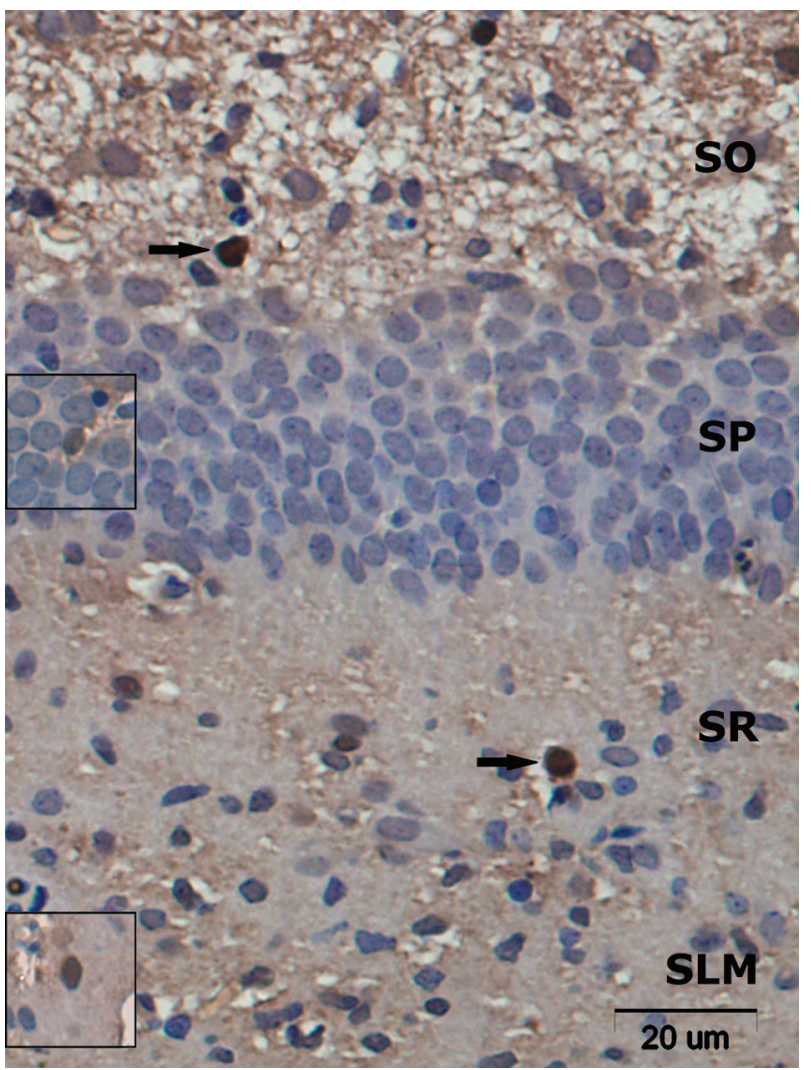

Figure 1. CR-immunopositive neurons in CA1 region of hippocampus in control neonatal rat. CR-positive cells are present in layers: stratum oriens (SO, arrowed), stratum pyramidale (SP, in frame), stratum radiatum (SR, arrowed), stratum lacunosum-moleculare (SLM, in frame). CR-immunoreactivity was detected as described in Methods

$(++)$ staining intensity were present. In both groups of animals in hilus there were similar neurons as in stratum moleculare and stratum granulosum. In some cells of MSG-treated rats intensely stained processes of different length were present (Figures 3 and 4).

\section{Morphometry of calretinin-immunoreactive cells in hippocampus of monosodium glutamate-treated neonatal rats}

Morphometric studies demonstrated that the density of all hippocampal cells (CR-positive and CR-negative) in P10 rats after MSG treatment significantly decreased by $43 \%$ in comparison with control group $(13.29 \pm 10.49$ vs. $23.43 \pm 13.26$, respectively; Kruskal-Wallis, $\mathrm{p}<0.05)$. The difference in the mean total density of CR-immunopositive nervous cells in CA1 region and dentate gyrus with hilus between MSG-treated and control neonatal rats was statistically not significant $(0.41 \pm 0.7 v s .0 .34 \pm 0.6$, respectively). Also the mean $\mathrm{CR}$-immunopositive

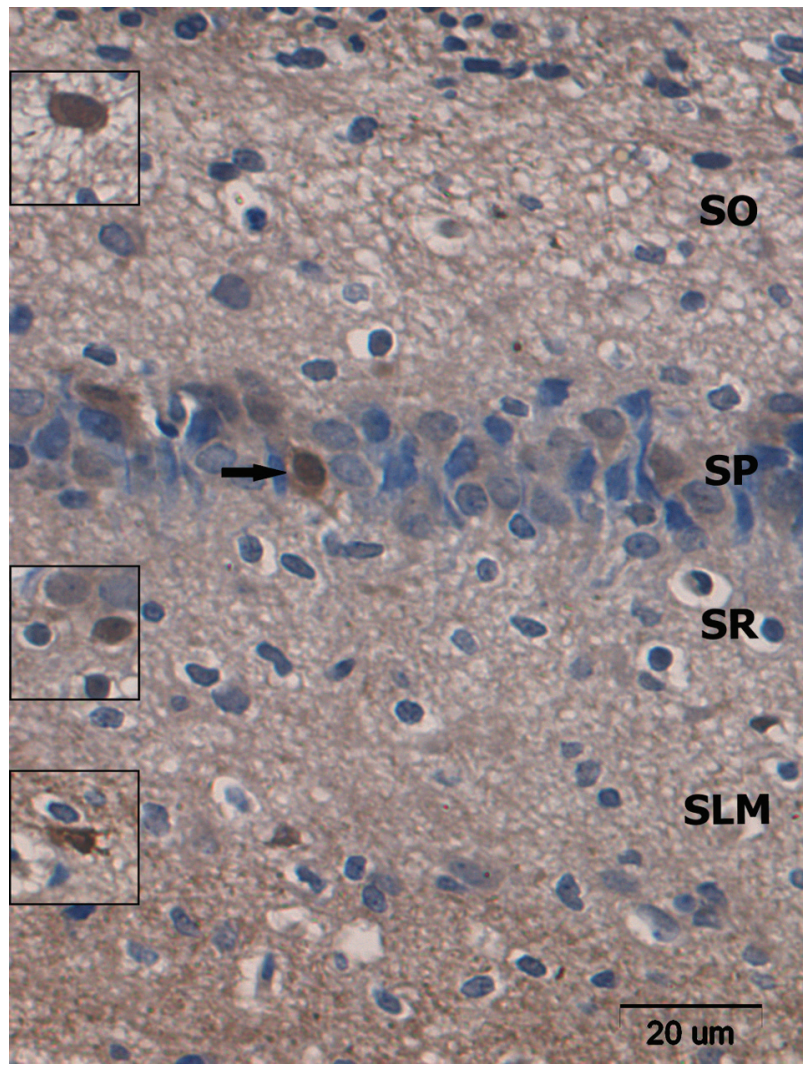

Figure 2. CR-immunopositive neurons in CA1 region of hippocampus in monosodium glutamate-treated neonatal rat. CR-positive cells are present in layers: stratum oriens (SO, in frame), stratum pyramidale (SP, arrowed), stratum radiatum ( $\mathrm{SR}$, in frame), stratum lacunosum-moleculare (SLM, in frame). CR-immunoreactivity was detected as described in Methods

cells percentage ratio to all cells in the experimental group $(2.96 \% \pm 5 \%)$ was similar to the control group $(2.13 \% \pm 3.9 \%)$.

However, in stratum pyramidale of hippocampal CA1 region a statistically significant increase in the average density of CR-immunopositive cells was observed in MSG-treated rats (Figure 5). There was also an increase in average percentage ratio of CR-immunopositive cells in this layer from $0.45 \% \pm 1.1 \%$ to $7.34 \% \pm 4.7 \%$. The average percentage ratio of immunostained cells was also increased in hilus from $0.26 \% \pm 0.8 \%$ to $3.22 \pm 4.9 \%$ (Figure 6 )

However, the percentage increase in the density of CR-immunopositive cells in these layers is caused by the significant decrease in total density of all cells. In stratum moleculare of dentate gyrus there was a statistically significant decrease in the average density of CR-immunopositive cells from $0.95 \pm 0.9 / 2.5 \times 10^{-3} \mathrm{~mm}^{2}$ to $0.25 \pm 0.4 / 2.5 \times 10^{-3} \mathrm{~mm}^{2}$ (Kruskal-Wallis, $\mathrm{p}<0.05$ ), whereas the percentage ratio of the cells to 


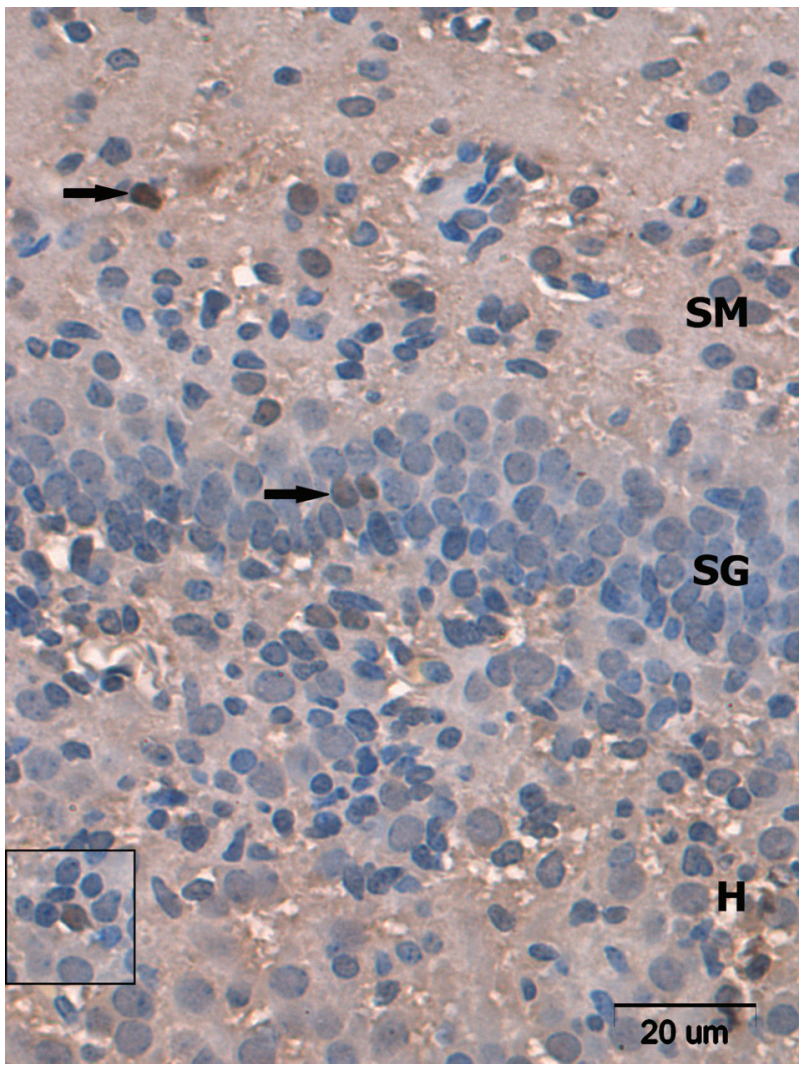

Figure 3. CR-immunopositive neurons in dentate gyrus with hilus in neonatal control rat. CR-positive cells are present in layers: stratum moleculare (SM, arrowed), stratum granulosum ( $\mathrm{SG}$, arrowed), hilus ( $\mathrm{H}$, in frame)

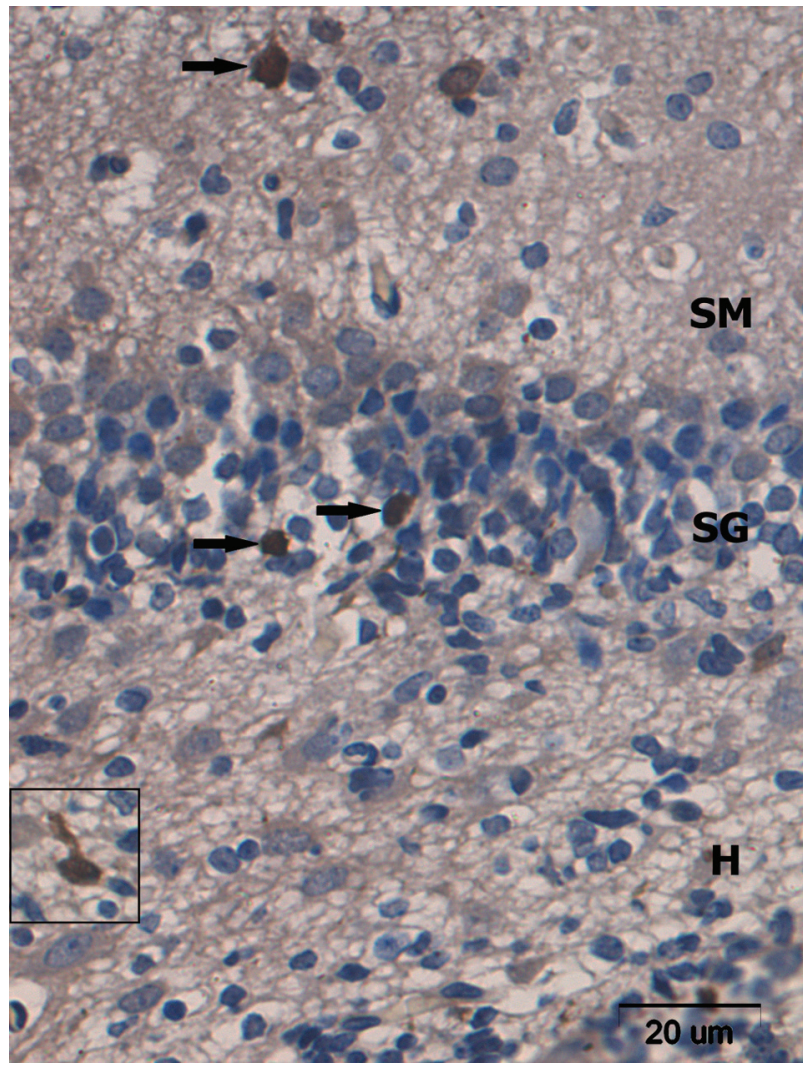

Figure 4. CR-immunopositive neurons in dentate gyrus with hilus in neonatal, monosodium glutamate-treated rat. CR-positive cells are present in layers described in the legend to Figure 3

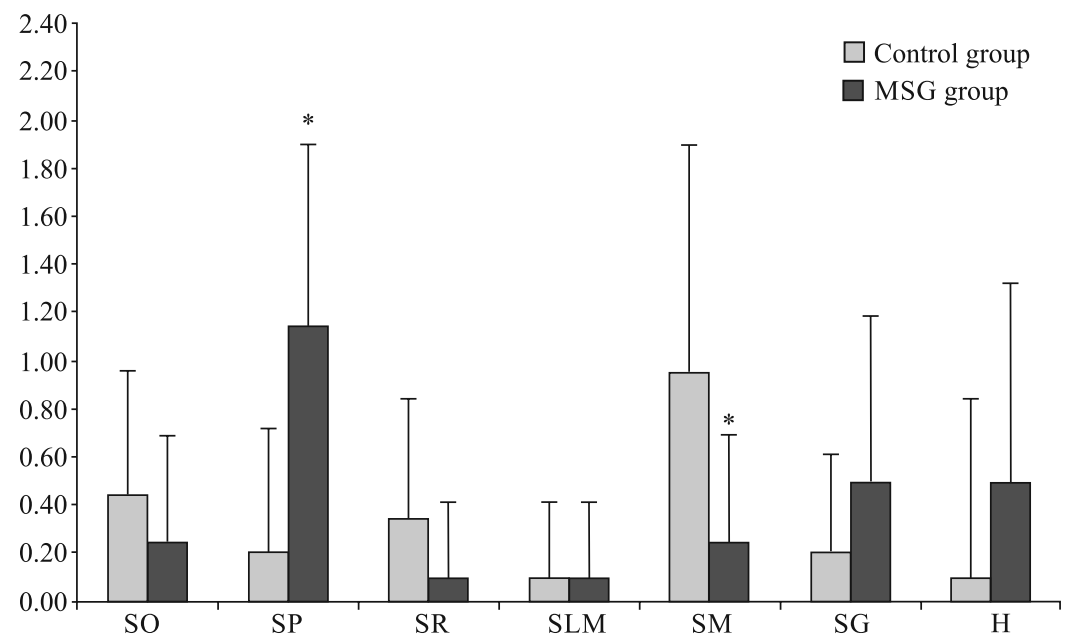

Figure 5. The density of CR-immunopositive cells in cell layers of CA1 region of hippocampus and dentate gyrus with hilus in monosodium glutamate-treated and control neonatal rats. Data shows mean density of CR-immunopositive cells in the area of $2.5 \times 10^{-3} \mathrm{~mm}^{2}$ averaged from 10 rats as described in Methods. Bars represent standard deviation; *statistically significant difference between control group and MSG group (Kruskal-Wallis, p < 0.05) related to the same layer. Abbreviations as in the legends of Figures 1 and 3 


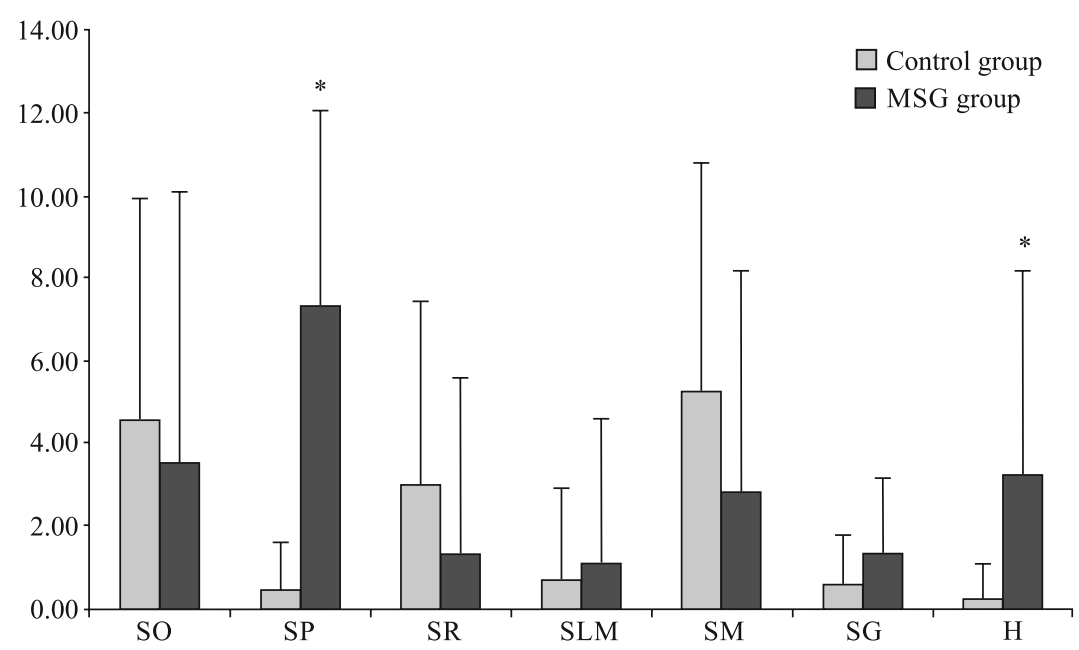

Figure 6. Relative density of CR-immunopositive cells in cell layers of CA1 region of hippocampus and dentate gyrus with hilus in control and neonatal rats. The results described as a ratio of the CR-positive cells density/density of all cells are expressed in percentage; *statistically significant difference between control group and MSG group (Kruskal-Wallis, $p<0.05$ )

all cells was similar in both groups (Kruskal-Wallis, $\mathrm{p}>0.05$ ) (Figures 5 and 6).

Substantial differences between MSG-treated and control neonatal rats were present in the evaluation of digital immunostaining intensity of the studied protein in hippocampal neurons. The statistically significant increase in CR-immunostaining intensity from 154.82 $\pm 12.5 \mathrm{ou} / \mu \mathrm{m}^{2}$ to $166.17 \pm 13.3 \mathrm{ou} / \mu \mathrm{m}^{2}$ (ANOVA, $\mathrm{p}<0.1$ ) in hippocampal CA1 region and from 149.81 $\pm 12.7 \mathrm{ou} / \mu \mathrm{m}^{2}$ to $173.08 \pm 11.6 \mathrm{ou} / \mu \mathrm{m}^{2}$ (ANOVA, $\mathrm{p}<0.01$ ) in dentate gyrus with hilus was demonstrated after MSG treatment (Figure 7).

\section{Discussion}

Our results demonstrated considerable, $43 \%$ decrease in the density of all cells in hippocampal CA1 region and dentate gyrus with hilus in P10 rats after MSG treatment. Such substantial decrease of cells is difficult to explain. However, some CR-negative neurons were morphologically changed in a way which may suggest neuronal death. Thus, the cell density loss may probably be related to the appearance of excitotoxicity phenomenon, which was suggested by results of previous studies [27-29]. It has been established that the excitotoxicity caused by different factors leads to serious neuronal disorders and even death of nervous cells. E.g. as a result of calcium ionophore A23187 action there was a $48 \%$ decrease in the number of neurons in rat neocortical cultures and under the influence of $\mathrm{N}$-methyl-D-aspartate and kainate there was a $32-40 \%$ loss of the cells in vitro [28]. In vivo studies revealed $11.5 \%$ loss of pyramidal neurons in

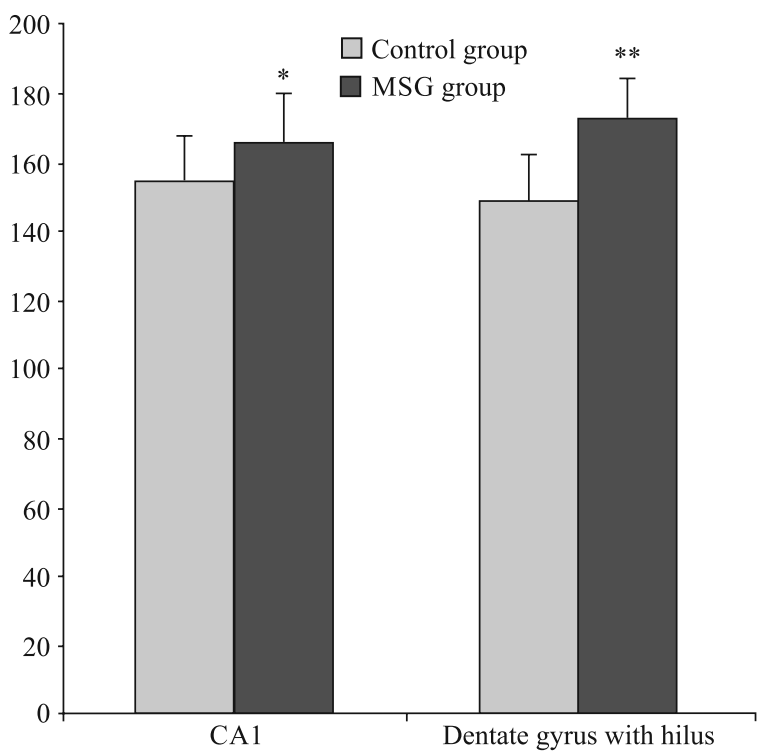

Figure 7. The intensity of immunostaining of CR-positive cells in CA1 region of hippocampus and dentate gyrus with hilus in neonatal rats. The staining intensity was measured as described in Methods; *statistically significant difference between control group and MSG group (ANOVA, $p<0.1$ ); **statistically significant difference between control group and MSG group (ANOVA, p < 0.01)

hippocampal CA1 region in 60 days old rats under the influence of MSG administrated to neonatal animals at 1, 3, 5 and 7 day of postnatal life [29]. In contrast to these observations we found much higher decrease of neurons' number in hippocampal CA1 region, although we did not specifically counted the pyramidal 
neurons. The much younger postnatal age of rats in our study could explain the difference between ours and Beas-Zarate et al. results.

Interestingly, we did not find differences in the density of CR-immunopositive cells in the studied brain areas between MSG-treated and control neonatal rats. Moreover, the average percentage ratio of CR-immunopositive cells to the density of all cells also did not change significantly in both studied groups. However, in stratum pyramidale of CA1 region and in hilus of dentate gyrus there was a significant increase in percentage ratio of CR-immunopositive cells. It may be related to the decrease of CR-negative cells density in these layers, which affects the CR-positive cells percentage ratio. Our results indicate the lack of statistically significant decrease in the density of CR-immunopositive cells under the influence of MSG, which may indicate that neurons containing calretinin have higher ability to survive than other types of neurons. This may be due to the fact that calretinin regulates the calcium homeostasis during increased calcium ions influx resulting from excitotoxicity, and thus reflecting neuroprotective effect of calretinin. Literature data also indicate that calretinin has a protective influence on neurons via buffering cellular calcium levels. In the in vitro studies it was demonstrated that the loss of cortical CR-immunopositive cells in response to calcium ionophore A23187 and excitatory amino acids was much smaller than that of CR-negative cells [28]. Protective properties of calretinin and calbindin D28k which protect cells against glutamate-induced cytotoxicity in transfected neuroblastoma retina hybrid cells N18-RE 105, were also demonstrated [30]. However, in area postrema of adult rats CR-immunopositive neurons were not protected against glutamate-induced neurotoxicity [32]. This finding could have been caused by lower cytoprotective properties of CR in adult individuals as the highest calretinin levels were observed in rat hippocampal neurons in the early period of postnatal life [1], or by various sensitivity of different brain regions to the damaging factors.

Moreover, our studies demonstrated statistically significant increase of digital CR-immunostaining intensity in nervous cells of CA1 and dentate gyrus with hilus of P10, MSG-treated rats. This may indicate the neuronal response to increased levels of calcium ions in neurons during excitotoxicity phenomenon. Owing to this response, it can be assumed that calretinin exerts a considerable $\mathrm{Ca}^{2+}$-buffering effect which in consequence leads to its protection of nervous cells against deleterious effects of $\mathrm{Ca}$ ions. Thus, the density of CR-immunopositive neurons may not alter substantially in MSG-treated rats, because high levels of calcium ions may be buffered by the calcium-buf- fering properties of calretinin. Furthermore, CR-immunopositive cells represent a certain sub-population of inhibitory GABAergic interneurons. They express both GABA and glutamate receptors [33-35]. The increase of glutamate levels may lead to physiological changes in cells containing $\mathrm{CR}$, i.e. in inhibitory GABAergic interneurons, to prevent the excitotoxicity, and thus to alter the CR expression in these cells. Moreover, in adult rats glutamate decarboxylase (GAD) activity alterations were found in GABAergic neurons after subcutaneous MSG administration to neonatal animals [36]. These studies indicate that in adult rats that were treated with MSG during neonatal life, in hippocampal neurons there is a significant increase of GAD activity included in GABA synthesis from glutamate. The authors of this paper suggest that in case of excitotoxicity induced by MSG during early developmental stages substantially modifies the functionality of GABAergic neurons [36]. This may be related with the MSG-induced calcium binding proteins activity alterations including calretinin.

In short, our observations revealed the increase of calretinin immunoreactivity in neurons of all CA1 region and dentate gyrus with hilus layers in P10 MSG-treated rats. The density of CR-positive cells was similar in MSG-treated group and control group. However, the density of all cells considerably decreased as a result of MSG treatment. MSG may affect the hippocampal GABAergic interneurons' response reflected in the increase of CR immunoreactivity in P7-P10 rats. The increased expression of CR may lead to its neuroprotective effect via its $\mathrm{Ca}^{2+}$ buffering properties. MSG did not affect CR-positive cells in contrary to CR-negative neurons as manifested by a relatively constant level of the density of CR-immunopositive cells after MSG treatment and decreased density of CR-negative cells. Further studies may reveal the functional importance of calretinin expression in the hippocampal neurons of different age groups of rats subjected to neonatal MSG administration.

\section{References}

1. Jiang M, Swann JW. Expression of calretinin in diverse neuronal populations during development of rat hippocampus. Neuroscience. 1997:81:1137-1154.

2. Ulfig N. Expression of calbindin and calretinin in the human ganglionic eminence. Pediatr Neurol. 2001;24:357-360.

3. Ulfig N. Calcium-binding proteins in the human developing brain. Adv Anat Embryol Cell Biol. 2002;165:1-92.

4. Schwaller B. Calretinin: from a simple $\mathrm{Ca}^{2+}$ buffer to a multifunctional protein implicated in many biological processes. Front Neuroanat. 2014;8:1-7.

5. Barinka F, Druga R. Calretinin expression in the mammalian neocortex: a review. Physiol Res. 2010;59:665-677.

6. Mattson MP. Excitotoxic and excitoprotective mechanisms: abundant targets for the prevention and treatment of neurodegenerative disorders. Neuromol Med. 2003;3:65-94. 
7. Mattson MP, Rychlik B, Chu C, Christakos S. Evidence for calcium-reducing and excito-protective roles for the calcium-binding protein calbindin-D28k in cultured hippocampal neurons. Neuron. 1991;6:41-51.

8. Głażewski S, Danysz W. Receptory dla aminokwasów pobudzających w ośrodkowym układzie nerwowym i ich rola w procesach plastyczności oraz toksyczności dla komórek. Post Biol Kom. 1992;19:145-161.

9. Hamilton NB, Attwel D. Do astrocytes really exocytose neurotransmitters? Neuroscience. 2010;11:227-238.

10. Shigemoto R, Kinoshita A, Wada E et al. Differential presynaptic localization of metabotropic glutamate receptor subtypes in the rat hippocampus. J Neurosci. 1997;17:7503-7522.

11. Endoh T. Characterization of modulatory effects of postsynaptic metabotropic glutamate receptors on calcium currents in rat nucleus tractus solitarius. Brain Res. 2004;1024:212-224.

12. D'Ascenzo M, Fellin T, Terunuma M et al. mGluR5 stimulates gliotransmission in the nucleus accumbens. P Natl Acad Sci USA. 2007;104:1995-2000.

13. Vizi ES, Kiss JP. Neurochemistry and pharmacology of the major hippocampal transmitter systems: synaptic and nonsynaptic interactions. Hippocampus. 1998;8:566-607.

14. El Falougy H, Kubikova E, Benuska J. The microscopical structure of the hippocampus in the rat. Bratisl Lek Listy. 2008;109:106-110.

15. Nitsch R, Ohm TG. Calretinin immunoreactive structures in the human hippocampal formation. J Comp Neurol. 1995;360:475-487.

16. Czéh B, Hajnal A, Seress L. NADPH-diaphorase positive neurons of the rat hippocampal formation: regional distribution, total number and colocalisation with calcium binding proteins. Prague Med Rep. 2005;106:261-274.

17. Gulyás AI, Hájos N, Freund TF. Interneurons containing calretinin are specialized to control other interneurons in the rat hippocampus. J Neurosci. 1996;16:3397-3411.

18. Siucińska E. Neuroprzekaźnik hamujący w plastyczności kory mózgu. Kosmos. 2005;54:195-212.

19. Moser MB, Moser EI. Functional differentiation in the hippocampus. Hippocampus. 1998;8:608-619.

20. Olney JW. Brain lesions, obesity and other disturbances in mice treated with monosodium glutamate. Science. 1969;164:719-721.

21. Olney JW, Ho OL. Brain damage in infant mice following oral intake of glutamate, aspartate or cysteine. Nature. 1970;227:609-610.

22. Olney JW. Glutamate induced neuronal necrosis in the infant mouse hypothalamus. An electron microscope study. J Neuropathol Exp Neurol. 1971;30:75-90.
23. Oser BL, Carlson S, Vogin EE, Cox GE. Oral and subcutaneous administration of monosodium glutamate to infant rodents and dogs. Nature. 1971;229:411-413.

24. Al-Jaberey NAA-S, Jaffar AA, Al-Salihi AR. Morphometry of the postnatal development of rat hippocampal capillaries. J Fac Med Baghdad. 2006;48:445-453.

25. Caley DW, Maxwell DS. Developmental of the blood vessels and extracellular spaces during postnatal maturation of rat cerebral cortex. J Comp Neurol. 1970;138:31-47.

26. König JFR, Klippel RA. A stereotactic atlas of the forebrain and lower parts of the brain stem. Williams and Wilkins: Baltimore; 1963.

27. Rajagopal SS, Lakshminarayanan G, Rajesh R et al. Neuroprotective potential of Ocimum sanctum (Linn) leaf extract in monosodium glutamate induced excitotoxicity. Acad $J$. 2013;27:1894-1906.

28. Lukas W, Jones KA. Cortical neurons containing calretinin are selectively resistant to calcium overload and excitotoxicity in vitro. Neuroscience. 1994;61:307-316.

29. Beas-Zárate C, Pérez-Vega M, González-Burgos I. Neonatal exposure to monosodium L-glutamate induces loss of neurons and cytoarchitectural alterations in hippocampal CA1 pyramidal neurons of adult rats. Brain Res. 2002;952:275-281.

30. Isaacs KR, Wolpoe ME, Jacobowitz DM. Vulnerability to calcium-induced neurotoxicity in cultured neurons expressing calretinin. Exp Neurol. 2000;163:311-323.

31. D'Orlando C, Celio MR, Schwaller B. Calretinin and calbindin D-28k, but not parvalbumin protect against glutamate-induced delayed excitotoxicity in transfected N18-RE 105 neuroblastoma-retina hybrid cells. Brain Res. 2002;945: 181-190.

32. Jászai J, Farkas LM, Gallatz K, Palkovits M. Effects of glutamate-induced excitotoxicity on calretinin-expressing neuron populations in the area postrema of the rat. Cell Tissue Res. 1998;293:227-233.

33. Fujise N, Liu Y, Hori N, Kosaka T. Distribution of calretinin immunoreactivity in the mouse dentate gyrus: II. Mossy cells, with special reference to their dorsoventral difference in calretinin immunoreactivity. Neuroscience. 1998;82:181-200.

34. Caiati MD. Is GABA co-released with glutamate from hippocampal mossy fiber terminals? J Neurosci. 2013;33:1755-1756.

35. Pettit DL, Augustine GJ. Distribution of functional glutamate and GABA receptors on hippocampal pyramidal cells and interneurons. J Neurophysiol. 2000;4:28-38.

36. Ureña-Guerrero ME, López-Pérez SJ, Beas-Zárate C. Neonatal monosodium glutamate treatment modifies glutamic acid decarboxylase activity during rat brain postnatal development. Neurochem Int. 2003;42:269-276.

Submitted: 1 July, 2014

Accepted after reviews: 23 October, 2014 Available as AoP: 7 November, 2014 